\title{
CUESTIÓN DE ESTADO: VIOLENCIA Y CRISIS
}

\section{Humberto Márquez Covarrubias}

Resumen: El proceso histórico de formación del Estado corresponde a un proyecto de sociedad emanado de las luchas y contradicciones sociales. En función de los intereses que enarbola, el Estado mexicano moderno adquiere una composición política que troquela el marco institucional y el conjunto de políticas que implementa de modo que alienta energías colectivas acordes a la correlación de fuerzas que soportan al poder y la dinámica de acumulación. Las políticas económica, social, política y cultural corresponden al proyecto de sociedad estatal enmarcado en el sistema mundial capitalista. Con la implantación del modelo de desarrollo neoliberal se agudizan las desigualdades y contradicciones sociales, y el Estado entra en una profunda crisis de legitimidad. Para continuar implementando el ciclo de reformas neoliberales el Estado recurre al uso de la violencia como dispositivo de control social y factor de preservación del régimen de acumulación articulado por capitales rentistas y predadores que desvanecen el tejido social y agudizan la conflictividad social. Los sectores populares ofrecen respuestas variadas, desde el consentimiento y la indiferencia hasta posiciones críticas y la resistencia.

palabras Clave: Estado, política, violencia, crisis, México.

*Docente-investigador y responsable del programa de Doctorado en Estudios del Desarrollo de la Universidad Autónoma de Zacatecas, México. 
Авstract: The process of State formation entails an historic societal project arising from the conflict found in social contradictions. In its historical and political formation, the modern Mexican State and with it the institutions within it, the interests that defend it, the policies it applies and the collective energies that propel it become a balance of power that sustains it, embodying a societal project to which it is committed and directed, through economic, social, governmental and cultural policies. With the adoption of the neoliberal capitalist development model, inequalities and social contradictions were made more acute, and the State arrived at a crisis of legitimacy. To continue implementing the cycle of neoliberal reforms, the State turned to the use of violence as a method of social control and a element of the preservation of the regime of accumulation practiced by predatory capital that tore at the social fabric and aggravated social conflict. The popular sectors offered various responses, from acquiescence and indifference through critical postures and resistence.

Keywords: State, policy, violence, crisis, Mexico. 


\section{DEVENIR DEL ESTADO MEXICANO}

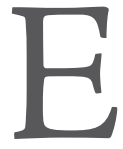

n el proceso histórico de formación del Estado se confrontan las visiones e intereses de las clases sociales hasta que un determinado bloque social logra institucionalizar su proyecto y entonces dispone de la capacidad para dirimir los diversos conflictos e intereses de la sociedad (Oliver, 2015). El entramado de instituciones, leyes y mediaciones, en conjunción con el sistema político, partidos y procesos democráticos, conforman un Estado que representa el proyecto del bloque social dominante y teje las relaciones de poder que reproducen el orden social vigente cuyo cometido principal es que el andamiaje institucional legitime y sostenga los mecanismos económicos y sociales de la acumulación de capital en una espiral orientada a maximizar las ganancias.

En el espacio de la subalternidad se moldea a los gobernados como una masa social dispuesta a otorgar el consentimiento a los procesos vertebradores de la sociedad contemporánea, la valorización de capital y los procesos de la democracia burguesa. Para el común de la ciudadanía la configuración estatal aparece como un intrincado andamiaje institucional provisto de un poder invencible que promulga leyes, pronuncia discursos rectores, difunde la ideología oficial, troquela la ciudadanía, organiza rituales cívicos, acota la participación política y detenta el «monopolio legítimo de la violencia» (Oliver, 2015). Un complejo de instituciones legales, administrativas y políticas cumplen la función de controlar a la población mediante el ejercicio de las atribuciones ejecutiva, legislativa y judicial al cargo de las cuales se encuentra la burocracia política, la tecnocracia y los dirigentes políticos. La formación ideológica acorde a la visión dominante es cultivada en el sistema educativo, moldeada por intelectuales orgánicos y difundida por los medios de comunicación. La observancia de orden y disciplina está encomendada a las fuerzas policiales y militares que disponen del reducto de los centros de detención y las cárceles. Determinaciones verticales inducen la toma de decisiones y suponen un carácter obligatorio, en consecuencia su implementación va de arriba abajo, aunque presuntamente están sancionadas 
por la carta constitucional y el andamiaje legal, o en su caso obedecen a decisiones inmediatas, contingentes o coyunturales, incluso puede tratarse de acuerdos secretos y discrecionales, pero en todo caso se invocan metas irrenunciables como el bien de la nación, la democracia, el respeto a la legalidad, el crecimiento económico, la generación de empleo y la seguridad pública. La razón de Estado es apelada en consideración a cálculos sobre la coyuntura política y la correlación de fuerzas. Los actos de poder y las enmiendas normativas son justificadas en el marco de un impoluto Estado de derecho, pese a que en casos como el mexicano la ausencia de un poder judicial independiente impide hablar con veracidad de un estatuto con esa catadura.

El discurso del poder ha presentado al propio Estado mexicano como la fiel cristalización de un proyecto nacional que reivindica los intereses y aspiraciones de la mayoría de la población, y no como la concreción del proyecto de la clase dominante. En esa narrativa mitológica el origen del Estado se remonta a la Revolución mexicana de 1910, que a la postre sería la primera revolución social del mundo en el siglo xx. Una gran justificación ideológica que perdurará en el imaginario social y se petrificará en el sistema político en las décadas postreras. Sin embargo, el Estado ha sido la agencia portadora del proyecto de la elite posrevolucionaria y la burocracia política enquistada en la administración pública la operadora del pacto populista y ejecutora del proyecto desarrollista. El proyecto pretende organizar una sociedad capitalista moderna plagada de contradicciones: en el frente externo estará marcado por la dependencia económica y subordinación política; en el plano interno podrá conformar una estructura social basada en las relaciones entre capitalis tas y trabajadores con el acompañamiento de un sector popular ampliado y el campesinado. Esas clases sociales tendrán representación política en el partido de Estado, mecanismo que permitirá evadir la aparición del régimen dictatorial militar, como ocurrió en gran parte de América Latina, pero no podrá escapar al dictamen de que encubre una «dictadura perfecta» (Vargas Llosa dixit). Cuando el proyecto desarrollista alcanzó su esplendor con el modelo de industrialización por sustitución de 
importaciones (ISI), los ciclos de crecimiento económico y la red de protección social, entonces se habló del «milagro mexicano» (Carmona, Montaño, Carrión y Aguilar, 1970). En buena medida el auge económico nacional se explica por el impulso de la llamada «época de oro del capitalismo», entre la segunda posguerra mundial y la crisis de los setenta, durante la cual las grandes potencias capitalistas como Estados Unidos, Japón, Alemania, Francia, Italia y Reino Unido registran altas tasas de crecimiento. En ese marco los trabajadores mexicanos ocuparon una posición subalterna, tutelados por el Estado y controlados por la política corporativa y clientelar. La subordinación política impidió que la mayoría de los obreros y campesinos tuvieran una formación político-cultural de clase que les otorgará la conciencia y autonomía necesarias para impulsar un proyecto de emancipación y cambio social (Otero, 2006). Mientras el Estado mexicano mantenía las riendas políticas y económicas se sabía omnipotente. Sin embargo, la crisis del capitalismo mundial en los setenta y la llamada crisis de la deuda mexicana en los ochenta dieron al traste con el proyecto desarrollista y entonces se adoptó un nuevo modelo de acumulación llamado neoliberal, pero centrado en el papel del Estado como gestor del capital monopolista, lo cual acrecienta la subordinación del Estado al poder económico del capital global (Osorio, 2004).

A partir de la necesidad de colocar el excedente económico acumulado durante las décadas doradas de crecimiento de las economías centrales y de romper los límites espaciales para la valorización del capital (Harvey, 2012), los organismos financieros y comerciales internacionales imponen programas económicos de ajuste estructural que responden a la lógica expansiva de los capitales monopólicos multinacionales. El Es tado mexicano asume el modelo de desarrollo capitalista neoliberal y se reconvierte en una forma de poder político que representa un proyecto histórico sin asidero en la mitología nacional ni en el pacto populista que articulaba a las principales clases sociales de la nación; ahora el discurso del poder y el programa de gobierno se trascriben desde las nuevas tablas de Moisés, las cartas de intención del Banco Mundial y el Fondo Monetario Internacional que condicionan el acceso al crédito. Más que 
antes, las fuentes de sustentación del nuevo modelo provienen del exterior por lo que el capitalismo mexicano se inserta en una matriz de pura dependencia económica y subordinación política, con el agravante de que se ajusta por entero a los intereses imperialistas de Estados Unidos (Guillén, 2012).

Las instituciones son reorientadas para que garanticen las múltiples exigencias de los capitales financieros, industriales y comerciales que buscan acaparar el excedente económico, apropiarse de los activos y sectores públicos estratégicos y rentables, saquear los recursos naturales y explotar la abundante fuerza de trabajo barata que ha liberado el régimen populista.

El desmantelamiento del modelo desarrollista de corte nacionalista y la ruptura del pacto populista provocaron una acelerada descomposición del tejido social. Al no disponer de ningún relato que le brindara la legitimidad requerida, pues la falaz promesa de que por fin el país entraría al primer mundo no podría sostenerse por mucho tiempo, y para que pudiera ser funcional, eludiera el estallido social latente y mantuviera un mínimo de gobernabilidad, el Estado abrió las «válvulas de escape» por vías que acrecentaban la degradación social: informalidad, migración y criminalidad, además implementó programas asistencialistas para mantener con dádivas a los pobres que incrementaban su presencia en la escena social y endureció las medidas autoritarias de control social que incluían la cooptación, la censura y la represión, mientras tanto simulaba una apertura democrática y la defensa de los derechos humanos mediante la formación de instituciones supuestamente autónomas.

\section{RECONVERSIÓN CONSERVADORA}

El Estado que emerge en el periodo posrevolucionario y campeará en gran parte del siglo $\mathrm{xx}$ despliega el proyecto nacionalista que convierte a las clases subalternas en una masa social carente de autonomía, sobre todo el campesinado (Villafañe, 1986). Con la asunción del neoliberalismo el modelo eco- 
nómico-político termina por desconectarse de las necesidades y expectativas populares. El desvanecimiento del paternalismo propicia una sociedad civil que va perdiendo los tenues rasgos de heteronomía que la dibujaban (Bayle, 2008). La decadencia de la hegemonía del nacionalismo revolucionario y la imposición del proyecto neoliberal no representan una transición automática, pues entraña múltiples contradicciones, como la subordinación hacia las potencias del exterior y el autoritarismo hacia adentro. Para imponerse tiene que afrontar la resistencia de varios sectores sociales que reivindican postulados del desarrollo nacional, pero también de quienes proponen cambios sociales sustantivos. En lugar de alcanzar el consenso o la aceptación, el nuevo proyecto enfrenta una conflictividad social expresada en diversas formas de lucha y resistencia en el medio rural y urbano, que no obstante su amplitud también se caracterizan por la fragmentación. La oposición política se alimenta desde entonces de una amplia gama de organización y movimientos sociales que enarbolan diversas reivindicaciones sociales, económicas, políticas y culturales que, pese a no haber logrado sus objetivos, al menos han impedido la legitimación del proyecto neoliberal (Bartra y Otero, 2007).

Desde la implantación del nuevo patrón de acumulación a principios de los años ochenta del siglo pasado, la clase política dominante adquirió la consistencia figurativa de un gran partido del dinero y el orden (Oliver, 2012), una amplia coalición volcada en la nueva configuración estatal que inclinó la balanza del sistema de partidos al flanco derecho, divulgó la ideología neoliberal y copó los espacios del poder político en las diversas esferas gubernamentales y legislativas, además de que permeó con su discurso a los medios de comunicación hasta disolverse en el sentido común popular. Esta fuerza política emergente y triunfante tuvo el arrojo suficiente para derrocar el programa plasmado idealmente en la carta constitucional y de implantar un proyecto neoliberal plagado de contradicciones: periférico debido a la supeditación al capital global e intereses imperiales, conservador por derogar los principios mínimos de la revolución social, y reaccionario al afianzar puramente los intereses oligárquicos, atacar a las organizaciones de trabajadores y la calidad de vida del grueso de la población. 
El modelo neoliberal decreta la extinción de la organización económica derivada del pacto populista, en particular el descarrilamiento de los sectores obrero y campesino con medidas como el embate a los sindicatos independientes y el respaldo a los sindicatos de protección empresarial, la política de flexibilización del mercado laboral, la contención de los salarios, la precarización de los trabajadores y el deterioro de las condiciones de vida. Deroga la institucionalidad que respaldaba la economía campesina con dotación de tierras, subsidios, créditos, precios de garantía, canales de comercialización y, en contraste, fomenta la apertura comercial indiscriminada y el apoyo preferente a la agroindustria y los cultivos no tradicionales de exportación. Promueve la especialización productiva exportadora, sobre todo en las maquiladoras del sector automotriz, electrónico, aeroespacial y textil. Un capítulo subrepticio es la exportación de trabajadores que amortiguaba el problema del desempleo estructural y abría una dependencia de las remesas para cubrir la subsistencia de familias vulnerables, amén de consentir la operación de organizaciones criminales y tolerar la corrupción política con fuertes nexos empresariales. El programa de reformas neoliberales avanzaría progresivamente mediante el desmantelamiento y privatización del sector público y la ruptura del sector social vía el despojo de bienes comunes y derechos para abrir múltiples espacios al capital privado rentista que se alimenta de los recursos saqueados y la explotación del trabajo liberado para generar ganancias superlativas. El derrocamiento del modelo nacionalista y la adopción del proyecto neoliberal reorganizan la trama interna de relaciones sociales y políticas para favorecer a la nueva oligarquía y al capital multinacional que toma posesión de los sectores estratégicos y más rentables de la nueva configuración económica orientada a la exportación y transferencia de excedente bajo formas más severas de intercambio desigual. En conjunto se refuerzan los lazos de subordinación y dependencia hacia la principal potencia económica y política del orbe, Estados Unidos (Gandásegui y Castillo, 2010), en un contexto donde la gobernabilidad continuaba por cauces autoritarios, pese a la simulación de la apertura de procesos de- 
mocráticos y la defensa de los derechos humanos, hasta terminar en el extremo de militarizar la vida social, como sustituto del debate político y la construcción del consenso.

En comparación al modelo desarrollista impulsado por las clases dominantes del antiguo régimen nacional popular, el modelo neoliberal está incapacitado para al menos impulsar el crecimiento y generar suficientes fuentes de empleos formal (Calva, 2011). En contraste, se han multiplicado fenómenos lacerantes como la llamada heterogeneidad estructural, la pobreza, la migración y la violencia. No obstante, al ser un proyecto de clase, el proyecto neoliberal sí ha logrado cumplir el propósito primordial de concentrar poder y riqueza en una delgada elite social, pero a costa de una crisis humanitaria de enormes proporciones que aún no registra un desenlace final.

Un factor clave en la construcción de la coalición neoliberal fue la alianza estratégica de las fuerzas políticas de derecha y centro izquierda, éstas últimas dispuestas a asumir como suyas las políticas conservadoras y subordinadas a los requerimientos de la nueva oligarquía mexicana, las exigencias del capital global y los intereses geoestratégicos de Estados Unidos. Dicha convergencia se va tejiendo en las altas esferas del poder a partir del año axial de 1982 cuando estalla la crisis en el país y se agrava la disputa por el poder entre las fracciones nacionalistas y neoliberales que coexisten en la burocracia política estatal (Cordera y Tello, 2010). El diferendo es ganado por los neoliberales representados por políticos tecnócratas apoyados por los organismos financieros internacionales gestores de la crisis de la deuda. El proyecto neoliberal y la nueva camada de políticos toman las riendas del Estado durante las tres décadas posteriores. En algunos momentos han tenido que superar procesos electorales competidos mediante el consabido recurso del fraude electoral a nivel federal $(1988,2006,2012)$ para evitar a toda costa el arribo de políticos de corte nacionalistas propuestos por formaciones partidarias de centro izquierda. Esos episodios de prueba han generado una efervescencia y crispación social que no han podido ser capitalizadas por la oposición en la construcción de un proyecto alternativo consistente 
y realista, pero en cambio han servido para que el núcleo duro de la derecha dirigente amarre los lazos de unidad y afiance los espacios de poder para proyectarse hasta el presente y el futuro.

Con la reconversión del régimen político basado en el partido de Estado, el Partido Revolucionario Institucional (PRI) y una órbita de partidos satélites que jugaban el papel de comparsas o testigos de las determinaciones centrales del presidencialismo autoritario, la supuesta apertura democrático-electoral abre espacios de representación a los partidos emanados de aquella configuración inicial y paulatinamente reparte puestos en los gobiernos estatales, las presidencias municipales y los cabildos, en las cámaras de diputados y senadores a nivel federal y estatal, además de que en la presidencia de la República permite la alternancia electoral sólo por el flanco derecho del espectro ideológico. En dos sexenios consecutivos (2000-2012) arriba el Partido Acción Nacional (pan) al poder Ejecutivo federal con Vicente Fox y Felipe Calderón. Los procedimientos democráticos se reducen a la vía electoral pero sólo benefician a un sector conservador derechista liderado por empresarios y políticos del PAN vinculados al conservadurismo y la extrema derecha. La supuesta transición política fue más de fachada, pues la concesión de la presidencia de la República a este partido político no puso en riesgo el modelo de acumulación neoliberal ni los intereses oligárquicos. En cambio nunca se reconoció el triunfo electoral del frente de centro-izquierda representado sucesivamente por el Frente Democrático Nacional, la Coalición por el Bien de Todos y el Movimiento Progresista con las candidaturas de Cuauhtémoc Cárdenas en el primer frente y Andrés Manuel López Obrador en las últimas dos coaliciones. Distintas prácticas fraudulentas como la compra y coacción del voto, las campañas de odio y desinformación, la turbiedad en los organismos electorales, el gasto millonario de las campañas, entre otras corruptelas, alteraron los procesos electorales hasta vaciarlos del contenido democrático que presumían. No obstante, la secuencia de fraude-alternanciafraude no detuvo la continuidad del proyecto económico y político trazado por el partido del dinero y el orden. Ahora con el retorno del PRI 
al gobierno federal para el periodo 2012-2018 asciende una fracción política conocida como el grupo Atlacomulco que rearticula a la tecnocracia, la burocracia política y los jefes de los partidos políticos para favorecer a los intereses exclusivos de la elite social mexicana asociada al capital multinacional, y como medidas iniciales destraba el procesamiento legislativo de las reformas neoliberales que de alguna manera quedaron entrampadas en el paréntesis de la alternancia electoral, pues el panismo no supo erigirse como clase política dirigente y más bien dio muestras de diletantismo político, autoritarismo y corrupción.

El reagrupamiento de la clase política dirigente derivado del retorno del PRI al gobierno de la República toma carta de naturalización en la esfera parlamentaria y extraparlamentaria. Predomina el triunvirato de derechas integrado por el PRI, el PAN y el PRD, además de otros partidos comparsas, cuyo cometido es preservar y profundizar el proyecto neoliberal para terminar de privatizar y en gran medida desnacionalizar la economía mexicana y favorecer a los capitales monopólicos mediante la cesión de los recursos nacionales y los bienes comunes, además del despojo de derechos sociales y económicos, mecanismos que pueden ser denominados genéricamente como acumulación por despojo (Harvey, 2012). La coalición partidaria de derechas es la cara visible del partido del dinero y el orden que mantiene una unidad de propósitos en torno al proyecto neoliberal y controla al Estado y sus instituciones. El Pacto por México formado por el Ejecutivo y los jefes de los partidos políticos forman el frente extraparlamentario que dicta las reformas neoliberales que aprobaran automáticamente las cámaras de diputados y senadores controladas por la triada de derechas. Bajo este mecanismo se han pactado las reformas neoliberales de tercera generación (trece reformas legislativas que incluyen la privatización de la renta petrolera, la precarización laboral, la evaluación punitiva del magisterio y demás) y se han distribuido los principales puestos y cargos, tanto los de representación electoral como los magistrados, consejeros y fiscales de organismos supuestamente autónomos como ocurre en el Poder Judicial de la Federación, el Instituto Federal Electoral (IFE, ahora INE), 
entre otros. En la línea de mando aparece subordinado el ámbito parlamentario y gubernamental donde figuran políticos formalmente electos en los comicios, aunque algunos como los legisladores plurinominales son designados indirectamente, no por el voto directo sino por la votación proporcional, lo cual permite que la burocracia de los partidos coloque a sus operadores políticos predilectos, quienes tomarán las grandes decisiones electivas de los grupos parlamentarios.

No obstante, la crisis de legitimidad que caracteriza al modelo económico-político propicia que el poder del dinero haga un fuerte llamado al orden para garantizar la seguridad del capital y el Estado, más que la seguridad de la ciudadanía y menos la de los sectores subalternos. Pero no es una autodeterminación de la oligarquía, pues sigue los lineamientos del poder imperial. La Iniciativa Mérida (antes Alianza por la Seguridad y la Prosperidad de América del Norte, aspan), programa hermanado del Tratado de Libre Comercio de América del Norte (TLCAN) es la carta de navegación de la política de seguridad nacional. Los gobiernos neoliberales adoptan la política de seguridad basada en los principios de la «guerra contra las drogas» de Estados Unidos para declarar la "guerra contra el narcotráfico» que señala a un enemigo interno (los narcotraficantes) y justifica la militarización del país. La espiral de violencia asciende vertiginosamente sin lograr el objetivo de desarticular a las organizaciones criminales, más bien consolida la economía criminal, que se diversifica en el rango de actividades ilícitas y en la cobertura territorial, y se consolida como una fuente de ganancia extraordinaria, una renta criminal, al inhibir la competencia en el marco del prohibicionismo y la violencia armada, y al controlar los mercados con altos precios y el respaldo del sector financiero, empresarial y político para lavar fuertes sumas de dinero negro. El miedo colectivo se esparce hasta alcanzar grados de esquizofrenia y se jus tifica la política de mano dura en un círculo vicioso de violencia, corrupción y degradación social que, sin embargo, es aprovechado virtuosamente para restañar la legitimidad perdida por el Estado. 
Los procesos democráticos forman parte del mecanismo de sustentación política del régimen y sus personeros, pero lo hacen mediante el autoritarismo electivo (Oliver, 2015). En esa lógica perversa las alusiones al Estado de derecho se esgrimen para justificar la aplicación de «todo el peso de la ley» a los opositores, lo cual incluye formas encubiertas de amedrentamiento y represión, cuando no encarcelamiento por motivos políticos e implementación de tácticas de contrainsurgencia; en contraste los grupos aliados y los sectores potentados tienen reservados de antemano espacios exclusivos para entablar negociaciones amistosas y condescendientes.

Las instituciones promotoras de la democracia burguesa liberal reciben grandes tajadas de recursos públicos y una enorme propaganda mediática pese a que su desempeño institucional es severamente cuestionado por la falta de transparencia e imparcialidad. Más allá de las pasiones desatadas, los procesos electorales no han ganado confianza ni certidumbre. En diversos hechos, de manera frecuente, se han documentado elecciones, en los distintos niveles, plagadas de irregularidades. Los comicios ni siquiera cumplen mínimamente las propias reglas del juego acordadas por los participantes y, a la vez, beneficiarios del sistema de partidos políticos. Entre otros aspectos se reitera el tráfico de dineros que exceden escandalosamente los límites permisibles sin esclarecer su procedencia, la tolerancia de diversas infracciones procedimentales que pudieran significar incluso la cancelación del registro a candidaturas y partidos, la persistencia de campañas de denostación y odio, la carencia o simulación de debate político y confrontación de ideas, la censura y la mercantilización de la información en los medios de comunicación, la práctica sistemática de compra y coacción del voto y la resolución de controversias acorde a las determinaciones oficiosas. Estos aspectos se refieren sólo a la violación a las normas electorales, pero el fondo del asunto estriba en que el sistema de partidos políticos representa exclusivamente los intereses del poder del dinero y el orden, no reivindica los intereses reales de las clases y sectores subalternos, llámese trabajadores asalariados y no asalariados, campesinos, pueblos 
originarios, estudiantes, afectados por el despojo, la precarización, el desempleo y la migración, etcétera. A final de cuentas el llamado Estado de derecho es un estatuto creado por grupos políticos coaligados alrededor de un proyecto histórico de dominación y la puesta en práctica atiende a criterios de interpretación que facilitan el control social y la manipulación institucional de conformidad a la visión e intereses emanadas de las altas esferas del poder estatal. Las demandas sociales de mayor calado no son incrustadas en el proyecto estatal y los partidos, sindicatos y movimientos que hacen llamados al cambio son férreamente acotados. Bajo el rediseño constitucional y normativo la carta de derechos tiende a estrechar las libertades civiles y los derechos ciudadanos, a privilegiar los intereses del capital corporativo, a justificar el llamado al orden y la disciplina social, y a castigar a los adversarios y líderes considerados como agentes peligrosos por los estrategas del régimen político.

\section{CONTRADICCIONES DEL NUEVO BLOQUE DE PODER}

La nueva oligarquía prohijada por el neoliberalismo y la burocracia política rectora tejen relaciones de poder diferenciadas: afuera se subordinan a los capitales multinacionales y las directrices políticas que representa Estados Unidos; adentro despliegan una gestión del despojo y sometimiento de las clases subalternas.

La subordinación a los intereses económicos, políticos y militares de Estados Unidos impulsan a la clase política mexicana a fijar una agenda de contrarreformas que está alineada con el proyecto geoestratégico de reordenar el continente americano (Gandásegui y Castillo, 2010). El papel de México en el mundo, y en particular en América Latina, se deteriora a pasos agigantados, al punto en que se le considera como el «patio trasero» de Estados Unidos. México se convierte en ariete del proyecto de configuración de un supra Estado virtual en América del Norte dirigido por Estados Unidos que paulatina- 
mente busca absorber a los Estados clientes de Centroamérica, Colombia y el Caribe mediante acuerdos bilaterales o regionales de libre comercio y seguridad (Oliver, 2015). Aún en el contexto de grandes transformaciones políticas en América del Sur, con la asunción de gobiernos de centro izquierda, también llamados progresistas, que reivindican un cambio de políticas en el horizonte posneoliberal (Veltmeyer, 2010), proyectos no exentos de controversias, la clase política mexicana renuncia a una política autónoma y nuevas formas de integración regional no asimétricas; en lugar de ello acepta subordinarse a las determinaciones de los grupos de poder estadounidenses que prescriben las políticas económicas, políticas, ideológicas y militares.

El desmantelamiento de la industrialización sustitutiva de importaciones, que permanecía en un orden periférico y dependiente, fue suplido por uno modelo peor que conducía a la franca desindustrialización nacional, donde México aparece como un contenedor de industrias del sector automotriz, electrónico, textil y aeroespacial, pero en condiciones operativas de ensamblador a partir de la abundancia de trabajadores baratos y desorganizados. De hecho gran parte de la «economía mexicana» se ha convertido en un atado de actividades rentistas subordinadas a distintas expresiones del capital predador: ficticio, extractivo y criminal.

El régimen político neoliberal implementa una gestión por el despojo y la militarización que no puede ser caracterizada sino como una gobernabilidad autoritaria (Oliver, 2015). La alta burocracia formada o persuadida por las ideas tecnócratas de corte neoclásica y neoliberal concibe el ejercicio de gobierno como una esfera alícuota al sector empresarial por lo cual considera que la administración pública debe adoptar prácticas gerenciales orientadas por criterios del mundo empresarial, promueva esquemas de asociación público-privada para la implementación de obra pública, proyectos de infraestructura y servicios; al mismo tiempo crea un ambiente institucional favorable a los grandes negocios que incluye la exención, evasión y regreso de impuestos, un marco legal para el acaparamiento de tierras y aguas, y la precarización del trabajo; además de garantizar la seguridad de la inversión, diseña políticas de 
control de la población para contener o disuadir a opositores de los megaproyectos en curso.

La conducción política sigue una ruta vertical cuya línea de mando comienza en las altas esferas, donde se acuerdan las macropolíticas neoliberales con los organismos internacionales según lo que se ha dado en llamar el Consenso de Washington y que en el país se traducen fielmente bajo las reformas de ajuste estructural, que ya tienen un camino recorrido de tres generaciones. En el ámbito nacional las elites económicas y políticas celebran acuerdos no declarados pero que son determinantes para la conducción de las instituciones estatales. La implementación de las grandes decisiones sigue la directriz del Ejecutivo sobre los poderes Legislativo y Judicial; las determinaciones avanzan en sentido vertical en la estructura de mando para llegar a los grupos parlamentarios que están atentos a las indicaciones centrales del Estado y del empresariado, no a las demandas de sus electores; también alcanzan a los organismos autónomos, permean a los gobiernos estatales y municipales; finalmente se aplican de manera irrestricta en los sectores subalternos.

En ningún momento se cumple el principio teórico democrático de que la soberanía popular dimana del pueblo. En lugar de ello el poder político toma la forma de fetiche y se encarna en quienes detentan los puestos de poder (Dussel, 2006). Una vez desaparecido el pacto populista, la cadena de mando-obediencia modifica el tratamiento sobre los sectores subalternos, para ello se reeditan las formas de control corporativo y se asume el trato clientelar. Los grandes medios audiovisuales, principalmente las televisoras privadas, pero cada vez más los dispositivos digitales y sus redes de comunicación, emprenden una tarea primordial de enajenar a la población, de sujetar al sujeto. La conciencia colectiva es colonizada para formar una subjetividad acorde a las pautas del mercado y de la política convencional. Incluso se llega al extremo de infantilizar a las grandes audiencias con la programación de espectáculos degradantes y la difusión de campañas que demonizan o criminalizan los movimientos sociales y las protestas que cuestionan la gestión autoritaria y la dinámica predatoria de los 
capitales, encima atemorizan a la población a través de la difusión descarada de espiral de violencia desatada por la supuesta guerra contra el narcotráfico.

\section{EMPRESARIADO PROHIJADO POR EL ESTADO}

El proyecto neoliberal privilegia los intereses empresariales de la elite a costa de desmantelar la economía nacional y contrariar las necesidades populares. No obstante los empresarios potentados no son innovadores ni generadores de empleos formales de calidad, por lo contrario son rentistas que se apropian de bienes comunes y nacionales, imponen formas severas de flexibilización y precarización del trabajo, controlan mercados cautivos y reciben cuantiosos recursos públicos de manera continua. La enorme polarización social tiene un registro evidente en la plutonomía y el precariado. Actualmente, sólo 16 familias en México amasan una fortuna que suma 144 mil 500 millones de dólares equivalente al 15.2 por ciento del producto interno bruto (PIB) de una economía considerada la número 16 más grande del mundo y en el otro extremo coexisten, según cifras oficiales, 55.3 millones de pobres. Los multimillonarios mexicanos no han surgido del esfuerzo propio, como suele argumentar la ideología empresarial, sino que han sido engendrados por el Estado y siguen viviendo de la depredación de los recursos públicos. Las grandes empresas gozan de exenciones fiscales: las principales 450 empresas dejan de pagar un equivalente a 400 mil millones de pesos al fisco, pese a que las grandes empresas apenas generan el 33 por ciento de los empleos, mientras que el conjunto de medianas y pequeñas empresas generan el 66 por ciento de empleos y están condicionadas a cumplir todas sus obligaciones fiscales y tienen una alta tasa de mortandad. Las grandes empresas pueden llegar a pagar tasas mínimas de impuestos, hasta un exiguo 1.7 y hasta 1.5 por ciento, en cambio los trabajadores pagan 35 por ciento. Además de las facilidades y favores fiscales, el empresariado paraestatal dispone de otros medios de enriquecimiento, claramente tiene su base en el programa de privatización de empresas y activos públicos donde se forman grandes 
consorcios, como ocurre recientemente con las concesiones mineras a Grupo México, Peñoles, Carso y otros; y de manera continua acceden concesiones de obra pública y proyectos de infraestructura, en tanto que los bancos privados, como Banorte e Interacciones, grupos financieros emparentados con el Estado, otorgan créditos a los gobiernos estatales y municipios en condiciones que dejan en la astringencia a las arcas públicas. El dinero público se mina para favorecer a los grandes grupos empresariales mexicanos. El enriquecimiento de la nueva oligarquía neoliberal tiene un mecanismo de seguridad, la socialización de las pérdidas. Cuando los nuevos empresarios entran en fase crítica, el Estado acude a rescatarlos. En los años ochenta las 20 principales empresas estuvieron al punto de colapsar, pero el gobierno destinó 12 mil millones de dólares iniciales para apoyarlos; otro tanto ocurrió con el llamado rescate carretero de los empresarios que se habían apropiada de las autopistas construidas por el Estado, para ellos se destinaron 180 mil millones de pesos; los bancos privatizados que incluían a las principales empresas entraron en curso de quiebra también fueron rescatados con el Fondo Bancario de Protección al Ahorro (Fobaproa), ahora Instituto para la Protección al Ahorro Bancario (IPAB), que generó un pasivo de 712 mil millones de pesos. En estos casos se trata de fondos públicos sustraídos de los contribuyentes para acrecentar las arcas de empresarios multimillonarios y enriquecerlos aún más. En las crisis económicas recurrentes gran parte de la población pierde sus empleos, ahorros y patrimonio familiar sin que se active ningún programa de rescate.

De manera complementaria a la alternancia electoral acordada por las elites políticas a principios del siglo actual han saltado a la palestra pública diversos grupos delictivos en varias regiones del país. A partir de la narrativa oficial se han hecho más que visibles las organizaciones de traficantes de drogas y en especial los cabecillas que son iconos de una cierta cultura popular. Estas mafias aumentan su dominio territorial en la medida en que se descompone el Estado y surge una especie de proto Estado en el que campea la corrupción, no necesariamente por vacíos del poder estatal sino que en muchos casos opera la connivencia de los poderes locales y regionales con los grupos criminales. No obstante, estos 
grupos alcanzan una cobertura nacional y transnacional. La expansión de sus capitales ocurre en momentos en que se deteriora la economía y el conjunto de la sociedad, se profundiza la crisis orgánica de la economía nacional y la pérdida de control político de las clases dominantes, así como la descomposición social provocada por el patrón de acumulación. El hecho significativo es la procreación de un capital criminal articulado a otras formas de capital que actúan entre la ilegalidad y la ilegalidad, más que de narcotraficantes envilecidos aflora un empresariado, la narcoburguesía, que obtiene una renta criminal, una ganancia extraordinaria.

\section{ESTADO NARCOTIZADO}

Actualmente México está compenetrado por el narco-capitalismo. La dinámica de acumulación de capital articulada por la economía criminal gira en torno a las drogas, que figuran como una de las mercancías emblemáticas de los mercados de consumo global con mayores márgenes de rentabilidad. Los grupos empresariales que se benefician con el sistema financiero y las inversiones extranjeras, en una economía de especulación, rentismo, sobreexplotación y despojo, interactúan en espacios contiguos donde se alternan formas legales e ilegales.

En gran parte del territorio nacional se expande el dominio de la economía criminal especializada en la producción, distribución y comercialización de drogas, el lavado de dinero y otros delitos que atentan contra la dignidad de la vida humana, tales como el homicidio, el secuestro, el robo, la extorsión, la trata de personas. Según el Departamento de Estado de Estados Unidos, con amplia injerencia en materia de seguridad en México, el fenómeno del narcotráfico cubre con amplitud a 21 estados del país (Sin embargo, 2015).

El mayor grado de putrefacción institucional aflora cuando el Estado mexicano en su etapa neoliberal decadente adquiere los rasgos de un Estado narcotizado donde se confunde la «guerra contra el narcotráfico» con la colusión, en distintos planos y niveles, entre instancias 
estatales y los grupos criminales, al punto en que adquieren notoriedad gobernadores y políticos señalados como partícipes de la economía criminal (Solís, 2013). El sometimiento de las instituciones regionales y locales a los grupos criminales y la tolerancia o connivencia de las autoridades y elites locales con el crimen organizado profundizan la crisis de representación y envilecen el sistema político. En todos los niveles se propaga la corrupción de las instancias oficiales (Pérez, 2008) por la tolerancia de las instituciones a las actividades ilícitas de los grupos criminales, el enriquecimiento súbito de esos grupos, las políticas de exclusión neoliberales y la falta de alternativas económicas populares. Adquiere preponderancia la formación del proto Estado criminal.

Paradójicamente la política prohibicionista y la guerra contra las drogas mantienen a buen resguardo el lucrativo negocio de las sustancias psicoactivas. La violencia desatada alienta diversos tipos de corrupción, la violación masiva de derechos humanos y la criminalización de sectores sociales marginados. En esa medida la espiral de violencia letal no podrá contenerse en tanto persista el modelo neoliberal, la oligarquía, la derechización política y la militarización.

\section{EMBATE ESTATAL}

A mitad del periodo de alternancia panista, en momentos en que el régimen político se resquebrajaba, debido a la ilegitimidad del gobierno que asumió el poder luego de un proceso electoral turbio con múltiples muestras de fraude, antes, durante y después de la jornada electoral, y ante la ola de protestas e inconformidad social, el gobierno toma la decisión de aplicar una política de mano dura, no dirigida directamente en contra de los opositores, pero sí para generar un clima de miedo donde la población se sintiera inerme y pidiera la acción del Estado, a la sazón la instancia que ejerce «el monopolio legitimo de la violencia». Es una estrategia de ingeniería sociopolítica y jurídica de populismo punitivo donde los estrategas políticos esparcen el 
temor entre las sociedad desinformada e impávida, se identifica un supuesto enemigo que amenaza la seguridad pública y se sugieren medidas extremas de exterminio, mano dura o tolerancia cero en contra de los supuesto infractores. Ante el clima de esquizofrenia grandes sectores de la población, impelidos por los medios de comunicación y lideres de opinión, se pronuncian paulatinamente por la intervención del Estado y la aplicación de mano dura contra aquel enemigo público (como en un tiempo lo fue el fantasma de la Mara Salvatrucha y ahora los son los narcotraficantes). El Estado plantea el problema, ofrece una solución y gana el respaldo de amplios sectores populares, de modo que si tenía un problema estructural severo, como la ilegitimidad, con ese apego pretende restañarlo y pavimentar el camino para continuar implementando las reformas neoliberales que siguen pendientes en su programa de gobierno.

El ejercicio del miedo colectivo ya se había ensayado con la supuesta epidemia mortífera de la influenza por el virus A (H1N1) que anunciaba una oleada inusitada de mortandad, pero en realidad inoculó y propagó un virus más poderoso, el miedo colectivo, el cual abrió una rendija a las grandes farmacéuticas para colocar enormes volúmenes de medicamentos que habían sido descatalogados de los mercados por ineficientes, como el Tamiflú. El Estado probó exitosamente en el terreno estrategias de control social, en este caso mediante la proclamación de la dictadura sanitaria (Márquez, 2014a). Después vendría la declaración de guerra interna.

La «guerra contra las drogas» proclamada por un Estado mexicano caído en una profunda crisis de ilegitimidad en realidad siguió los dictados de la doctrina de seguridad estadounidense basada en el anacrónico principio prohibicionista de las drogas - que criminaliza a los productores y traficantes de los países del sur, tolera a los consumidores del norte y preserva un nicho de mercado con altos márgenes de retorno para empresarios y financieros que incluso gozan de reputación social- y la esquizofrénica construcción de un «enemigo interno», en este caso los «narcotraficantes» (Calveiro, 2012). Aflora la contradicción entre dureza y docilidad: hacia adentro el Estado mexicano extiende la 
mano dura y hacia afuera muestra sumisión a la política estadounidense. Entorno a los discursos deterministas de una guerra interna gravita el perímetro de seguridad estadounidense que extiende sus fronteras hasta cubrir el territorio mexicano, su «socio comercial», para convertirlo en el patio trasero de operaciones industriales, vía maquiladoras, y policiales, a través de la militarización del territorio nacional.

La Iniciativa Mérida prescribe políticas de seguridad y suministra financiamiento para que un envalentonado presidente Calderón declare una guerra interna en contra de los mal llamados «cárteles del narcotráfico», con la aquiescencia de los legisladores, gobernadores y medios de comunicación, cuyas víctimas propiciatorias no serán precisamente individuos abstractos condensados en indicadores estadísticos, como el recuento diariamente actualizado lo señala, el necrófilo «ejecutómetro», en cuya lectura pretende resumirse el principio y fin de la problemática. Al final de cuentas, las víctimas reales de la violencia estatal y criminal son las clases y sectores sociales sometidos por la estrategia conjunta de despojo, sobreexplotación, rentismo y depredación que consolida el poder de la clase dominante y capitaliza a los grandes monopolios.

Una cifra imprecisa de miles de muertes (unas 150 mil) ha sido reconocida como el parte de guerra, un ascendente dato mortífero que en momentos de euforia era publicitado por las instancias oficiosas como signo inequívoco de que se estaba "ganando» la guerra. Empero, lo que realmente sucede es el desgarramiento del tejido social y la ruptura del principio de convivencia pacífica, sin que se afecte en realidad la producción, tráfico, venta y consumo de las drogas ni la comisión de otros delitos afines. Los impactos nocivos se multiplican: comunidades desplazadas, la desaparición forzada de más de 26 mil personas, los feminicidios y los atentados contra migrantes indocumentados en tránsito.

En ese marco, un par de acontecimientos cimbraron a la sociedad nacional e internacional: la matanza de los 72 migrantes indocumentados centroamericanos y la desaparición forzada de 43 estudiantes normalistas de Ayotzinapa, Guerrero. El segundo acto ha despertado un nuevo ciclo de protestas a nivel nacional sin que se aclaren los hechos. 
Representa un hecho emblemático de la profunda fractura entre la sociedad política y la sociedad civil; también significa la síntesis de la acumulación de la indignación colectiva que hace trizas el Estado de derecho y la legitimidad de las instituciones.

\section{LIBERAR EL CAPITAL, CRIMINALIZAR A LOS TRABAJADORES}

Adictos al credo neoliberal, los gobiernos derrumban obstáculos a los grandes flujos de capital y erigen barreras a los trabajadores. No obstante, la dinámica predadora del capital precipita avalanchas humanas cuyo avance es cerrado para que no se aproximen al suelo patrio de las grandes corporaciones. En una abigarrada mezcla de asuntos de «seguridad nacional» aparece la migración de personas sin papeles y el tráfico de drogas. En el mundo, los espacios geográficos preñados de mayores peligros para los migrantes indocumentados son el mar Mediterráneo y las rutas mexicanas. Por esos corredores transitan personas forzadas a buscar un trabajo asalariado en las sedes operativas de la economía mundial, Europa y Estados Unidos.

En México, la crisis migratoria está aparejada con los estragos del neoliberalismo y la violencia, pero adquirió preponderancia internacional con la noticia de la matanza de 72 migrantes indocumentados, en su mayoría centroamericanos, en el municipio de San Fernando, Tamaulipas. Conforme la indagación sobre la hecatombe fue aumentando se fue develando la práctica recurrente de violencia criminal y el acoso de las autoridades en contra de los migrantes sin papeles que buscan llegar a Estados Unidos (Márquez, 2014b). Otro capítulo terminó de enturbiar el panorama: el hacinamiento de menores indocumentados centroamericanos y mexicanos en centros de detención del sur de Estados Unidos, que fueron capturados por la policía estadounidense (Márquez, 2013a).

Para evitar que migrantes centroamericanos, sudamericanos y extracontinentales intenten arribar al territorio estadounidense, el gobierno mexicano implementa el programa Frontera Sur en el marco de la Iniciativa Mérida con financiamiento y asesoría estadounidense. 
Esa tarea se cumple con la militarización de la frontera sur de México, el aumento de la velocidad del tren carguero a fin de impedir el abordaje de la máquina en movimiento y el incremento sustancial de detenciones y deportaciones. Ahora el presidente mexicano Enrique Peña Nieto es reconocido como el «jefe deportador», mote que recientemente ostentaba su homólogo estadounidense Barack Obama. Con esas acciones el gobierno mexicano brinda un servicio de policía auxiliar.

\section{AUTORITARISMO GENERALIZADO}

La cultura política dominante corrompe el significado de nociones como desarrollo, democracia, derechos, ciudadanía, público y común. Al vaciarlas de contenido difunde el discurso ideológico y la ética empresarial emparentada con la visión de la modernización capitalista globalizante. La ideología proempresarial exalta el individualismo, el emprendedurismo, el consumismo, el sector privado, el mercado y la competencia (Márquez, 2013b). Esta concepción ideológica anhela la utopía del mercado total, el Estado mínimo y la libre concurrencia. Los empresarios son presentados como la imagen ideal del hombre de éxito, los consumidores compulsivos imprimen bríos a la forma de socialización cosmopolita y las intervenciones neocoloniales de los capitales predatorios representan instalaciones de la modernidad generadoras de riqueza y prosperidad. Los excluidos son motejados como los perdedores, incluso habrían nacido para perder, una justificación que propicia la reaparición de discursos y prácticas racistas, discriminatorias y xenófobas. Claro, para sostener este discurso es imprescindible ocultar los mecanismos económicos, sociales y políticos generadores de exclusión, pobreza y pauperización de la mayoría de las clases sociales. Entonces el éxito y riqueza de la plutocracia puede ser cínicamente exaltada.

Desde distintas posturas analíticas se reconoce que las sociedades modernas han conquistado el derecho a organizarse libremente y a ejer- 
cer los derechos políticos, pero es menos atendido el hecho de que la democracia burguesa se constriñe en la práctica a la emisión periódica del voto para que los sectores subalternos puedan elegir a quienes presumen representarlos en los órganos mediadores a sabiendas de que a la postre sólo serán representantes fieles y efectivos del Estado y los empresarios, no en balde la mayor parte de la clase política debe sus estatus a los poderes económicos y políticos preexistentes. La institucionalidad electoral se pavonea de la vigencia de los derechos políticos y los procedimientos democráticos, pero en los hechos promueve la pasividad del ciudadano, pues la mayoría de ellos permanece como espectador en las prolongadas temporadas donde no se celebran contiendas electorales, y cuando aparecen conflictos sociales son minimizados y tergiversados, o en su defecto encausados a instancias de negociación arbitradas por las mismas instancias estatales que suelen emitir dictámenes favorables a los grandes intereses corporativos. La misión es cancelar cualquier resquicio que signifique un triunfo social o una conquis ta que se traduzca en jurisprudencia progresista.

Las relaciones autoritarias y verticales articulan a la sociedad política, pero también dimanan sobre la sociedad civil (Oliver, 2012). La visión del empresariado pujante pauta las relaciones políticas que se expande al conjunto del sector social. El discurso emprendedor es un discurso simplista del engranaje social, pero funciona como mitología del ascenso social, sobre todo para los sectores populares y capas medias de la sociedad que se mueven por objetivos aspiracionales. No por nada la literatura de superación personal es la de mayor venta en el mercado librero. Desde ese mirador se establecen las directrices de los más diversos campos sociales, económicos, políticos y culturales. Sin embargo, el síndrome del autoritarismo crónico modula las relaciones asimétricas de poder y violenta las formas de convivencia en los ámbitos sociales subalternos.

Desde el estatismo autoritario, la producción de subjetividad subalterna está condicionada por las variantes de la política neocorporativa y la violencia. En su mayoría, los procesos de construcción de 
subjetividad social tienen como punto de referencia postulados y prácticas autoritarias, enajenadas y despolitizadas. Están permeando los más diversos ámbitos de la vida social (Oliver, 2015): patronal, sindical y gremial; científico, académico y educativo; artístico, cultural, religioso y deportivo; popular y étnico. Las relaciones sociales que persisten entre los de abajo también están compenetradas por las imposiciones y el autoritarismo, además de que se encuentran severamente lesionadas por el despojo y la desnacionalización, aunque también hay brotes significativos de indignación, protesta y rebelión.

\section{ESTADO DECADENTE}

La cuestión del Estado aparece entreverada por el proyecto histórico, las instituciones y las leyes que articulan la formación estatal, y por el pensamiento, la organización y la politización que configuran a la sociedad. Los procesos de formación del Estado atraviesan diversos momentos de lucha en pos de la preservación de los intereses creados o de la afectación de dichos intereses con miras al cambio social, pero en momentos de crisis las contradicciones se ahondan y las respuestas políticas de los bloques dominantes endurecen sus posiciones y recurren a la violencia para contener las pretensiones renovadoras.

Los componentes económicos y políticos del modelo de desarrollo capitalista neoliberal, a la sazón el proyecto del bloque de poder en México, están empantanados en una crisis. El andamiaje estatal pasa por un periodo de ilegitimidad y descomposición política. El sistema político articula una serie de instituciones que se han ganado el descrédito, desde los partidos y organismos electorales hasta las cámaras legislativas y el sistema judicial. La formación estatal entraña una contrariedad entre el discurso ideológico que contiene, por una parte, la médula del individualismo egoísta y el mito de la libre empresa y, por otra parte, ostenta una pesada formación estatista que confiere a la gestión pública la función de crear y administrar los mercados aunado 
a una abultada burocrática que estrangula y controla la vida social recurriendo a exceso de coercitivos y punitivos. El régimen político es neoliberal, burocrático y autoritario.

La descomposición institucional adquiere rasgos de mayor descaro en el ámbito regional y local. Luego del desmoronamiento del régimen de partido de Estado, un prolongado reinado del presidencialismo priista, y dada la carencia de reformas institucionales y judiciales durante el aciago periodo de alternancia electoral de las presidencias panistas, la mayoría de los gobernadores de las entidades federativas y los presidentes municipales de la triada conservadora (PRI, PAN, PRD) fueron tejiendo relaciones de complicidad que les permitiera gobernar sus territorios bajo una trama de corrupción, impunidad y despojo. Extendieron lazos dentro de la sociedad política para ejecutar de manera territorializada el programa neoliberal y estrategias electorales que asegurara la perpetuación de los grupos de poder político local con el concurso de financiadores empresariales y criminales. Engendraron nuevas camadas de ricos, beneficiarios de los programas gubernamentales, y apuntalaron a empresarios afines al proyecto político con la derrama selectiva de recursos públicos. Abarcaron también la órbita de la economía criminal donde el signo del dinero fácil y la violencia cruda siguen sus propias reglas del juego. Una amalgama de millonarios, nuevos ricos y criminales emerge a la superficie como la nata de una sociedad en proceso de fermentación.

Existe una correspondencia entre la dinámica de concentración del poder político y el deterioro de la reproducción social. Al tomar la forma de Estado servil del gran capital toma preponderancia la clase política neoliberal, los pactos políticos colaboracionistas, las medidas burocráticas antisociales, los discursos dirigentes demagógicos y las agresivas políticas de securitización. Los mecanismos del poder omnímodo están destruyendo aceleradamente el tejido social y ponen en predicamento el ciclo de producción y reproducción de la vida humana digna. 


\section{PURA SUBALTERNIDAD}

Durante la mayor parte del siglo xx, el esquema de mando-obediencia desplegó relaciones de poder asimétrico entre las elites políticas y las masas populares. La cultura política cristalizaba el aparente consenso social mediante la negociación, el pacto, la cooptación y la represión. Los acuerdos eran fraguados al calor del marco ideológico nacionalista y populista que permitía ciertas formas de participación de los grupos políticos institucionales en las mediaciones estatales. Las masas populares eran convocadas a participar, pero en condiciones de acendrada subalternidad (Oliver, 2015).

Bajo el modelo neoliberal la cultura política nacional populista es borrada para impulsar los intereses del gran capital privado y el concomitante autoritarismo político empresarial; en contrasentido, surge una oleada de luchas de resistencia a cargo de movimientos y sectores de la sociedad civil que reivindican la autonomía, la democracia y los derechos. La negociación política entre el Estado y la sociedad civil organizada es suspendida por la burocracia política y la tecnocracia, pero sin proponer un mecanismo alterno de diálogo público para dirimir los conflictos acrecentados por el despojo neoliberal. La cultura de derechas sólo está interesada en abogar por el proyecto oligárquico. Ante las movilizaciones y protestas la incompetencia política de la derecha gobernante deriva en la imposición de una lacerante cultura autoritaria obstinada en resguardar el orden en un contexto social caótico para catapultar los intereses económicos de los empresarios beneficiarios del régimen político.

Pese a la ruptura del pacto populista persisten amplios espacios y formas de subalternidad que disponen de elementos socioculturales que les confiere una cultura, identidad, valores, concepciones del mundo y vínculos con el sector público, asimismo mantienen vigente un papel funcional para el nuevo orden institucional y el sistema político. Los grupos subalternos que ahora contribuyen al sostenimiento del proyecto oligárquico neoliberal provienen del antiguo régimen político; en ese sentido se caracterizan como una masa amorfa, subalterna 
y despolitizada (Roux, 2005). No es extraño que añoren el régimen paternalista que los ha dejado en el abandono y pese a todo aún los sigue utilizando como base electoral o carne de cañón.

\section{UN LUGAR PARA LA RESISTENCIA}

Ante el poder reconcentrado del capital, el dinero y el poder político, que forman un agente colectivo promotor del proyecto histórico estatal dominante, el movimiento popular crítico aún permanece en etapa embrionaria. Está compuesto de movimientos minoritarios de incidencia local del medio rural y urbano interesados en temas muy acotados de los campos económico, político y cultural (Olvera, 2003). A menudo los métodos de lucha son reiterativos: marchas, plantones, manifiestos y mítines. Las mayores expresiones están concentradas en determinadas avenidas de las grandes ciudades, como la ciudad de México, epicentro del poder político y de las manifestaciones de protesta. Las llamadas megamarchas se han convertido en escenificaciones rituales que pretenden sintetizar la inconformidad social pero no logran afectar las fibras íntimas del poder establecido; en cambio son aprovechadas por los medios de comunicación para propagar la inconformidad y confusión entre los espectadores inmóviles para acentuar el divisionismo y generar el rechazo hacia los manifestantes. Así se expresa el poder comunicacional.

Es verídico el hecho de que las prácticas de resistencia popular actúan en el horizonte local y la acción directa, sin lograr avanzar, por el momento, a una articulación política más compleja donde la lucha de posiciones esté vinculada a un horizonte político nacional más amplio, incluso conectado al plano transnacional, donde en efecto se mueve el capital monopolista que comanda ahora la dinámica de acumulación reinante a nivel nacional. No se ha conformado tampoco un poder social, una fuerza política, dotada de una visión estratégica y un talante contrahegemónico que proponga una política democrática integral. Un dato sintomático es que persiste una subjetividad alienada en la gran mayoría 
que justifica una visión del mundo en tonos fatalistas que inhibe los ánimos formativos de un poder popular interesado en confrontar los ataques predatorios de los capitales rentistas, especulativos, extractivistas y explotadores.

Con todo, la cultura popular crítica representa la plataforma de lanzamiento de cualquier organización y movimiento que pretenda impulsar principios y prácticas democráticos y autonómicos en el seno de la sociedad civil y articular un gran movimiento social que reconstruya al Estado (Márquez, 2013b) bajo pautas democráticas que permitan al movimiento popular disolver la separación entre gobernantes y gobernados, afirmar el derecho a tener derechos (Rodotá, 2014) y asumir la tarea crucial de elevarse a una potencia social siguiendo el principio del poder obedencial (Dussel, 2006).

Desde una visión dinámica de la cultura popular crítica puede advertirse que los movimientos sociales son múltiples y diversos, inconexos y monotemáticos, episódicos y emergentes. Pero constituyen el espacio social autónomo y el lugar de la práctica social alternativa, donde a la vez que actúan, imaginan mundos posibles (Echeverría, 2010). En ese amplio espacio de construcción social se encuentran, por ejemplo, los movimientos urbanos que reivindican el derecho a la ciudad, los derechos sociales y ciudadanos, la paz y la seguridad humana, contra la corrupción y la impunidad, igual convergen movimientos sociales defensores de los bienes comunes naturales y en contra del despojo. Tiende a disolverse la división tajante entre el mundo urbano popular de los sindicatos, intelectuales, profesionistas, académicos y estudiantes del mundo rural que anuda las expresiones campesinas, indígenas y comunitarias. El cúmulo de violencias estatales y las víctimas del capital depredador actúan como factores de unidad de diversas organizaciones y movimientos que retoman imaginarios solidarios, aunque también la gestión del despojo y la violencia activan agresivos mecanismos de fragmentación y diferenciación de las víctimas que dificultan su encuentro y articulación en movimientos sociales de mayor calado. A pesar de todo están aflorando distintas vertientes de una emergente y autonómica cultura de la lucha 
social y la reivindicación de derechos que presagian la paulatina construcción de un movimiento social impulsor de nuevas formas de hacer política dentro y fuera de la órbita estatal bajo postulados como la democracia popular participativa y la autonomía comunitaria.

Nuevos sectores emergen en el ámbito social popular interesados en desplegar organizaciones y actividades autónomas frente al Estado e independientes de los partidos políticos (Otero, 2006). Actúan en la sociedad civil, pueblos y comunidades originarias de diversas regiones y entidades federativas. Se distinguen por una resistencia ciudadana y popular de tono crítico. Al estar desconectadas de la herencia paternalista y la pasividad despolitizada, adquieren nuevos rasgos ideológicos y culturales que les permite reivindicar sus derechos desde posiciones autónomas y formas organizacionales horizontales. Incluso algunas organizaciones y movimientos, más allá de formas de participación e inclusión, proponen otro tipo de relaciones sociales. Disponen de un bagaje político para ampliar y articular las formas de la democracia representativa con la democracia participativa, al propio tiempo que imprimen relevancia a la resistencia y la lucha social, amplían los horizontes de la política de la ciudadanía y los espacios públicos y comunitarios.

Una compleja cultura popular, progresista y emancipatoria coexiste entre trabajadores formales y precarizados, comunidades campesinas, pueblos originarios y grupos progresistas (Oliver, 2015). Preñada de viejas y nuevas ideologías y valores, considera entre sus reivindicaciones procesos de cambio en los campos económico, político e institucional, inquietudes intelectuales y éticas, además de otras coordenadas para la organización y concientización de la sociedad civil (González Casanova, 1983).

Esta subjetividad no está exenta de un debate sobre el carácter excluyente o complementario de las formas de lucha reformista y revolucionaria en un horizonte preñado de utopías y aspiraciones de cambio social (Bartra, 2011). En el variopinto espectro de organizaciones y movimientos sociales anida un poder potencial cuya proyección aún es difusa, pero 
abriga la esperanza de articular un movimiento popular que construya un Estado democrático, aunque algunos movimientos optan por la autonomía y la comunidad autogestionaria sin buscar relacionarse de ninguna forma al Estado.

\section{REFERENCIAS}

Bartra, Armando (2011), La utopía posible, México, La Jornada Ediciones. y Otero, Gerardo (2007), "Rebeldía contra el globalismo neoliberal y el TLCAN en el México rural: ¿del Estado corporativista a la formación políticocultural del campesiando?, Textual, núm. 50.

Bayle, Paola (2008), Biagini, Hugo y Roig, Arturo (dirs.), "Autonomía", Diccionario del pensamiento alternativo, Buenos Aires, Biblos.

Calva, José Luis (2011), “La economía mexicana en perspectiva”, Economía unam, vol. 1 , núm. 1.

Calveiro, Pilar (2012), Violencia de Estado. La guerra antiterrorista y la guerra contra el crimen como medios de control global, México, Siglo XXI.

Carmona, Fernando, Montaño, Guillermo, Carrión, Jorge y Aguilar Alonso (1970), El milagro mexicano, México, Editorial Nuestro Tiempo.

Cordera, Rolando y Tello, Carlos (2010), México: la disputa por la nación, México, Siglo XxI.

Dussel, Enrique (2006), 20 tesis de política, México, Siglo XXI.

Echeverría, Bolívar (2010), Modernidad y blanquitud, México, Era.

Gandásegui, Marco A. y Dídimo Castillo (2010), Estados Unidos. La crisis sistémica y las nuevas condiciones de legitimación, Buenos Aires, Clacso-Siglo XXI.

González Casanova, Pablo (1983), "La cultura política en México”, El Estado y los partidos políticos en México, México, Era.

Guillén, Arturo (2012), "México, ejemplo de las políticas anti-desarrollo del Consenso de Washington”, Estudos avançados, vol. 26, núm. 75.

Harvey, David (2012), El enigma del capital y la crisis del capitalismo, Madrid, Akal.

Márquez, Humberto (2013a), "El redoble de la migración forzada: inseguridad, criminalización y destierro", Migración y desarrollo, vol. 11, núm. 21. (2013b), "Malestar en la cultura: hegemon'a neoliberal, indignación y cambio social”, en Delgado, Raúl y Márquez, Humberto (coords.), El labe- 
rinto de la cultura neoliberal. Crisis, migración y cambio, México, Miguel Ángel Porrúa.

(2014a), "Sociedad en terapia intensiva: renta farmacéutica y sujeto medicado", Observatorio del desarrollo, vol. 3, núm. 12.

(2014b) ,"En lomos de la bestia: traveśas migratorias por los infiernos mexicanos", Observatorio del desarrollo, vol. 3, núm. 9.

Oliver, Lucio (2015), "Aproximaciones a la crisis del Estado mexicano", Memoria, núm. 255.

(2012), "Las formas espectrales de un régimen autoritario sin hegemonía y la nueva lucha por la construcción democrática popular”, Bajo el volcán, vol. 11, núm. 18.

Olvera, Alberto (2003), "Sociedad civil, gobernabilidad democrática, espacios Públicos y democratización: los contornos de un proyecto", IV Conferencia Regional istr-Lac, San José, Costa Rica.

Osorio, Jaime (2004), El Estado en el centro de la mundialización. La sociedad civil $y$ el asunto del poder, México, Fondo de Cultura Económica.

Otero, Gerardo (2006), "Formando democracia: formación político-cultural y vinculación desde abajo", Iconos, Revista de Ciencias Sociales, núm. 26.

Pérez, Carlos (2008), "El proceso de descomposición de las instituciones y el sentido de lo comunitario en los proyectos de sociedad”, El Cotidiano, núm. 152.

Rodotá, Stefano (2014), El derecho a tener derechos, Madrid, Tortta.

Roux, Rina (2005), El Principe mexicano: subalternidad, historia y Estado, México, Era.

Sin embargo (13 de abril de 2015),"EU lanza nueva alerta para viajar a 21 estados en México; preocupan secuestros, dice", Sin embargo, en: http://www.sinem bargo.mx/13-04-2015/1311782

Solís, José Luis (2013), "Neoliberalismo y crimen organizado en México: el surgimiento del Estado narco", Revista Frontera Norte, vol. 25, núm. 50.

Veltmeyer, Henry (2010), "La crisis global y Latinoamérica", Problemas del desarrollo, vol. 41, núm. 160.

Villafañe, Víctor (1986), La formación del sistema político mexicano, México, Siglo XXI. 